\title{
External Quilting: New Technique to Avoid Haematoma in Gynaecomastia Surgery
}

\author{
Alessandro Innocenti ${ }^{1,2} \cdot$ Ghezzi Serena $^{1} \cdot$ Marco Innocenti $^{1}$
}

Level of Evidence $V$ This journal requires that authors assign a level of evidence to each article. For a full description of these Evidence-Based Medicine ratings, please refer to the Table of Contents or the online Instructions to Authors www.springer.com/00266.

\section{Dear Sir,}

We read with great interest the article titled: "External Quilting: New Technique to Avoid Haematoma in Gynaecomastia Surgery" by Murugesan et al. The authors presented their personal technique adopting external quilting suture in gynaecomastia correction, with the aim of preventing haematoma and avoiding drain placement. We completely agree with the authors that seroma, when liposuction is included in gynaecomastia, and haematoma remain the most common early complications which may necessitate a return to the theatre $[1,2]$. According to the authors, we don't retain the use of drains which is mandatory for this type of surgery, unless a valid haemostasis is performed directly. The use of drains should be suggested only in patients with large amounts of breast gland removal or in the presence of a coagulation disorder, although the final choice for their insertions should be made during the operation. Nevertheless, we have some elements to discuss. Although the effort to minimize the length of the surgical access is very important in aesthetic surgery, a small incision about $1.5-2 \mathrm{~cm}$ in length in the inferior part of the areola allows a direct view of the surgical field during glandular resection, ensures valid control of haemostasis and permits internal quilting, leaving inconspicuous scarring. Internal quilting is not visible and therefore allows more satisfaction with the result in the immediate post-op avoiding any patients' displeasure due to track of the external marks. Internal quilting has no need to be removed, and maintaining, for a long time a firm connection of the adipocutaneous thoracic flap to the pec-

Alessandro Innocenti

a.innocenti@unifi.it

1 Plastic and Reconstructive Microsurgery, Careggi University Hospital, Viale Giacomo Matteotti 42, 50132 Florence, Italy

2 Plastic Surgery, University of Florence, Florence, Italy 


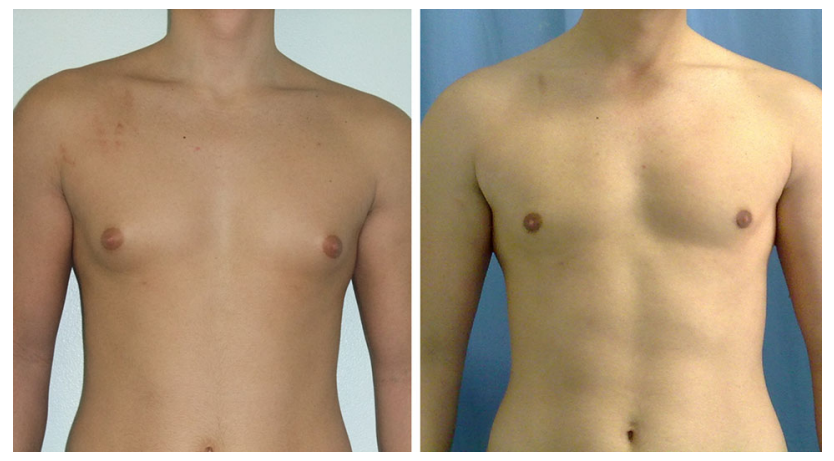

Fig. 1 (left) Preoperative view showing a grade II of bilateral gynaecomastia in a 19-year-old patient according to the Rohrich classification; (right) postoperative view showing a 2-cm-length scar placed at the inferior border of the areola. No presence of extraareolar scarring

toralis fascia, they could guarantee a better recontouring of the extra skin onto the new pectoralis profile, especially in the most severe form of gynaecomastia. Moreover, since seroma represents a popular complication, internal quilting, avoiding dead space permanently, can reduce the incidence of this common disorder especially in overweight patients. Although extra-areolar scar could be particularly visible, especially in the presence of pathological scarring, since a stab incision was performed in the anterior axillary line, a temporary drain should be considered; the drain's vacuum helps to avoid dead space as well as a compressive jersey medical dressing [3-5]. Moreover, although the incidence of breast cancer in males is very low, we retain that histological investigation is always recommendable even in the absence of clinical suspicion especially in young patients (Fig. 1).
Funding None.

\section{Compliance with Ethical Standards}

Conflict of interest The authors have no conflicts of interest to disclose.

Ethical Approval All the procedures performed in studies involving human participants were in accordance with the ethical standards of the institutional and national research committee and with the 1964 Helsinki Declaration and its later amendments or comparable ethical standards.

Informed Consent Informed consent is not required for this type of study.

\section{References}

1. Innocenti A, Ciancio F, Portincasa A, Parisi D (2017) Discussion: surgical management of Gynecomastia-subcutaneous mastectomy and liposuction. Aesth Plast Surg 41(4):983-984

2. Innocenti A, Melita D, Innoenti M (2018) Evaluation of glandular liposculpture as a single treatment for grades I and II gynecomastia. Aesth Plast Surg 42(6):1707-1708

3. Innocenti A, Ciancio F, Francesco M, Melita D, Innocenti M (2017) Comment to: "No-drain single incision liposuction pulltrough technique for gynecomastia. Aesth Plast Surg 41(4):990-991

4. Innoenti A, Melida D, Ghezzi S (2019) Closed-suction drains after subcutaneous mastectomy for gynecomastia: do they reduce complications? Aesth plast Surg 43(4):1124-1125

5. Innocenti A, Melita D, Ciancio F, Innocenti M (2017) Discussion: "Long-term follow-up of recurrence and patient satisfaction after surgical treatment of gynecomastia". Aesth Plast Surg 41(5):1242-1243

Publisher's Note Springer Nature remains neutral with regard to jurisdictional claims in published maps and institutional affiliations. 